\title{
Leaf photosynthesis of three typical plant species affected by the subsidence cracks of coal mining: a case study in the semiarid region of Western China
}

\author{
Y. LIU, S.G. LEI ${ }^{+}$, L.S. CHENG, W. CHENG, J.B. XIONG, and Z.F. BIAN \\ School of Environment Science and Spatial Information, China University of Mining and Technology, Jiangsu, \\ Xuzhou, 221116, China
}

\begin{abstract}
Increased attention has been paid to effects of coal mining subsidence on the growth of plants. Studying the changes of plants photosynthetic physiology under the disturbance of coal mining subsidence is the basis for understanding dynamic exchanges of plant energy and water at that mining area. The 52302 working face of the Shendong mining area was selected as the experimental site, with Artemisia ordosica, Caragana korshinskii, and Populus spp. as the research targets. Changes in leaf photosynthesis were monitored in plants at a subsidence crack area. We showed collapse cracks decreased soil moisture and caused drought stress. The photosynthetic capacity of leaves was reduced. Compared with plants from the control area, stomatal conductance, photosynthetic $\mathrm{CO}_{2}$ assimilation, and transpiration rate were reduced in all three plant species. The activity of PSII reaction center and electron transport at the donor and acceptor sites significantly decreased.
\end{abstract}

Additional key words: chlorophyll fluorescence; drought stress; ground cracks; photosynthetic physiology; plant disturbance.

\section{Introduction}

Coal is an important energy source in China, accounting for about $70 \%$ of the total energy consumption (Bian 2005). More than $95 \%$ of China's coal mining is carried out by means of well mining, which has resulted in large subsidence of the land in the mining areas and caused serious damage to the environment (Zhang et al. 2003). In recent years, the focus of coal mining in China has shifted westward, making the fragile ecology of the environment in the semiarid mining area deteriorating (Lei and Bian 2014). The most direct manifestation is the impact on the vegetation. Modern high strength coal mining has a great negative impact on the surface vegetation, thus, the vegetation coverage is lower than that at nonmining areas. In the mining process, a large number of cracks and mined out subsidence zones are formed on the ground surface and the soil water content in the areas with large fracture density is lower than that in the areas with low fracture density (Daniels 2010, Zang et al. 2010). Moreover, the soil nutrient content in the subsidence area is lower than that in contrasting areas (Wang et al. 2006, Zang et al. 2010). At the same time, because of the influence of the surface cracks, the internal relationships between the microbial and enzyme activities in the rhizosphere of plants have changed (Du et al. 2013). Strong stress induced by soil deformation also causes damage to plant roots in subsidence area. (Ding et al. 2013). Such dynamics eventually affects the absorption of water and nutrients by plant roots. Changes in the physical and chemical properties of the soil surface, the further deterioration of soil and water loss in mining areas, and the destruction of previous habitats for vegetation growth, all inhibit the growth of plants to some extent.

At present, research about the impacts of coal mining on plants mainly focuses on vegetation biomass (Qian et al. 2014), coverage (Wu et al. 2009), diversity analysis (Qiu et al. 2011), and indirect effects of soil damage caused by mining (Wang et al. 2014). In a study of the effects of the coal mining on the vegetation landscape in $\mathrm{Mu}$ Us Desert,

$\overline{\text { Received }} 13$ December 2017, accepted 20 July 2018.

${ }^{+}$Corresponding author; e-mail: Lsgang@126.com

Abbreviations: ABS/RC - absorption flux per RC; $\mathrm{AN}$ - ammonia nitrogen; $\mathrm{C}\left(\mathrm{CO}_{2}\right)$ - concentration of $\mathrm{CO}_{2}$ in the environment; $\mathrm{Chl}$ - chlorophyll; $\mathrm{CK}$ - control area; $\mathrm{DI}_{0} / \mathrm{CS}$ - energy dissipation per unit area; $E$ - transpiration rate; $\mathrm{ET}_{\mathrm{o}} / \mathrm{ABS}^{-}$quantum yield for electron transport $(\mathrm{at} \mathrm{t}=0) ; \mathrm{ET}_{\mathrm{o}} / \mathrm{RC}$ - trapping energy used for electron transport per $\mathrm{RC} ; \mathrm{ET}_{\mathrm{o}} / \mathrm{TR}_{\mathrm{o}}$ - probability that a trapped exciton moves an electron into the electron transport chain beyond $\mathrm{Q}_{\mathrm{A}}^{-}($at $\mathrm{t}=0) ; \mathrm{F}_{0} / \mathrm{F}_{\mathrm{m}}$ - thermal dissipation quantum yield; $\mathrm{F}_{\mathrm{v}} / \mathrm{F}_{\mathrm{m}}-$ maximal photochemical efficiency of PSII; $g_{s}$ - stomatal conductance; $\mathrm{M}_{0}$ - approximated initial slope of the fluorescent transient; OM - organic matter; PI - performance index based on absorbed light energy; $P_{\mathrm{N}}$ - photosynthetic $\mathrm{CO}_{2}$ assimilation rate; RC - reaction center; $\mathrm{SA}$ - subsidence area; SWC - soil water content; TN - total nitrogen; TP - total phosphorus; $\mathrm{TR}_{\mathrm{o}} / \mathrm{RC}$ - trapping flux leading to $\mathrm{Q}_{\mathrm{A}}$ reduction per $\mathrm{RC}$; $\mathrm{TR}_{0} / \mathrm{ABS}$ - maximum quantum yield for primary photochemistry $($ at $\mathrm{t}=0$ ); WUE - instantaneous water-use efficiency. Acknowledgement: The research was supported by the projects funded by National Key Research and Development Program (No. 2016YFC0501107), Special Project of Science and Technology Basic Work (No. 2014FY110800), and National Natural Science Foundation of China (No. U1361214). 
Qian et al. (2014) pointed out that the fragmentation of the landscape increased and the vegetation biomass decreased after coal mining. After investigation of vegetation restoration in mining area, Qiu et al. (2011) pointed out that the plant biodiversity in subsidence area was lower than that in unsubsidence area. In a study of the influence of coal mining on the soil and vegetation characteristics, Wei et al. (2014) pointed out that changes in the soil environment caused by coal mining affect the growth of plants. Zhang et al. (2017) studied the effects of the surface cracks caused by coal mining on soil characteristics and wheat growth. In this paper, the effects of soil cracks on many aspects related to both soil and plants were introduced. Water stress and nutritional stress were the main abiotic factors affecting leaf photosynthesis, while subsidence cracks had negative effects on these soil properties compared with non-subsidence area soils. In summary, previous research on the response characteristics of plants to coal mining have been carried out macroscopically, but studies conducted from the point of view of plant photosynthesis are scarce (Zhang et al. 2017).

At present, photosynthetic gas exchange and chlorophyll (Chl) fluorescence are the main methods used in plant photosynthesis research. Mastalerczuk et al. (2017) studied the gas-exchange parameters and morphological characteristics of festulolium under different nitrogen application conditions. Dąbrowski et al. (2017) investigated the changes of $\mathrm{Chl}$ fluorescence delay and gas exchange in perennial ryegrass under salt stress. Dąbrowski et al. (2015) investigated the Chl $a$ fluorescence of perennial ryegrass varieties under long-term exposure to shade. In addition, Dąbrowski et al. (2016) used Chl fluorescence to diagnose quickly the changes of PSII structure in ryegrass under salt stress.

The Shendong coal mine, the largest and most important coal base in the semiarid area of western China, is associated with serious ecological damage caused by coal mining subsidence. The 52302 coal mining face at the Shendong mining area was selected as the study area. Artemisia ordosica, Krasch (subshrub), Caragana korshinskii, Kom (shrub), and Populus spp. (deciduous tree) were selected for the study of plant photosynthesis and fluorescence responses to subsidence. A. ordosica and $C$. korshinskii, strongly drought-resistant and easy to survive, are important species for ecological restoration at the Shendong mining area (Wang 2011). Field investigation showed that Populus spp. has obvious quantitative advantages in the coal mining area, and the population density is larger than that of other plant species. The three subject species are widely distributed in the mining area (Wang 2011). For all of these reasons, A. ordosica, $C$. korshinskii, and dominant species of Populus spp. were selected as subjects of our investigation. The aims of this study were: (1) to analyze the changes of photosynthesis and $\mathrm{Chl}$ fluorescence responses in plant leaves under the influence of coal mining subsidence cracks; and (2) to analyze the influence mechanism of mining subsidence cracks on photosynthesis of plant leaves.

\section{Materials and methods}

Study sites: This study was carried out at the 52302 coal mining work face of the Shendong Coal Mine at the eastern edge of Mu Us Desert, Ejin Horo Banner, the Inner Mongolia Autonomous Region, West China (Fig. 1). The study area is dominated by annual grasslands, deciduous broad-leaved shrubs, and other desert plants. The study sites, with a total area of $376 \mathrm{~km}^{2}$ and an annual average temperature of $7.3^{\circ} \mathrm{C}$, were located within $110^{\circ} 05^{\prime} 00^{\prime \prime}$ to $110^{\circ} 20^{\prime} 00^{\prime \prime} \mathrm{E}$ and $39^{\circ} 27^{\prime} 00^{\prime \prime}$ to $39^{\circ} 15^{\prime} 00^{\prime \prime} \mathrm{N}$. The region is characterized by a typical arid and semiarid continental climate of a plateau with dry climate and low rainfall. Annual average rainfall and evaporation are $413.5 \mathrm{~mm}$ and 2,111.2 $\mathrm{mm}$, respectively. The main soil types are loess

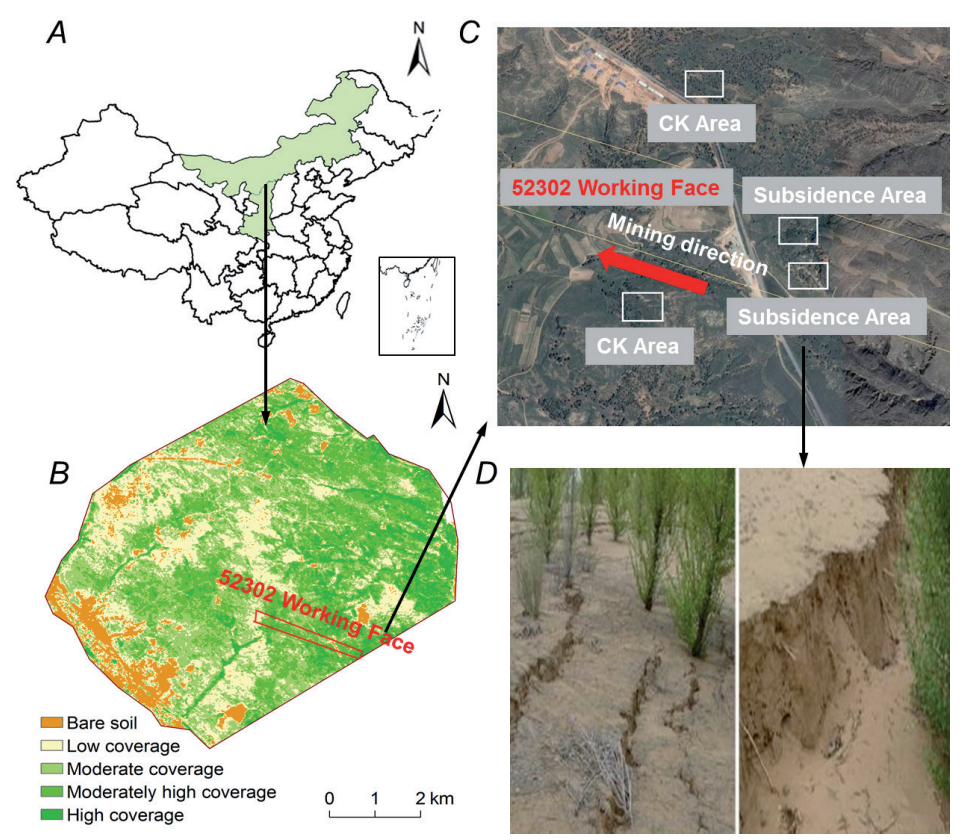

Fig. 1. The locations of the study region. ( $A$ - the geographic location of Daliuta coal mine; $B$ - the geographic location and vegetation cover of 52302 working face; $C$ - the location of the experimental plot; $D$ cracks in a collapse area). 
and aeolian sandy soil, with loose structure, poor erosion resistance, and vulnerable to wind erosion. Because of human production activities, the original vegetation at the mining area has been destroyed and replaced by artificial restoration species.

The 52302 working face is located at the southeast area of the Daliuta coal mine. It was first mined ten years ago, and is currently undergoing a second mining operation (Table 1S, supplement). The coal seam is buried at a depth of $220 \mathrm{~m}$ and $7 \mathrm{~m}$ wide for this area. Under these conditions, the surface of the earth is sinking violently and the deformation is concentrated. The subsidence cracks or sinking basin are formed rapidly on the ground surface. Investigated sites were primarily divided into two main categories: (1) coal-mining subsidence area (SA), with a large number of coal-mining subsidence cracks distributed on the ground surface; (2) control area (CK) outside the coal-mining subsidence area, with no coal-mining subsidence cracks.

Plant material: The types of vegetation at the 52302 working face are mainly deciduous bushes, hay prototype and desert type, with A. ordosica, C. korshinskii, Populus spp. as the main representatives of the psammophytic vegetation growth in semi-fixed sand, fixed sand, and sand dune lowlands. In order to eliminate the influence of plant age, leaf position, temperature, light intensity, air humidity, measurement time, and other factors, three kinds of plants (A. ordosica, C. korshinskii, and Populus spp.), with a consistent growth age, plant height, plant age, and the root system intact, were selected as the subjects. Three replicates of each kind of plant were measured at the two sample plots. When choosing plant leaves, according to the principle that the crown was not covered, the photosynthesis parameters of the first three mature leaves in the vertical downward direction of the main stem of the plant were measured, and three replicates for each selected leaf. The width of the selected cracks was between $30-40 \mathrm{~cm}$, with a depth of 2,500-2,580 $\mathrm{mm}$. The distance from the selected $A$. ordosica (three years old) and C. korshinskii (four years old) to the crack was about $50 \mathrm{~cm}$, and that of the Populus spp. (eight years old) was about $100 \mathrm{~cm}$.

Soil environment factor: In addition, the soil environment factors for the two sample fields were also investigated and listed in Table 2S (supplement). Soil sampling time was in July 2015, representing the summer of the study area. The position of sampling sites wtable 2 as recorded by a portable global position system (GPS) (eTrex Venture, Garmin, Lenexa, KS, USA). Removing litter from the soil surface before sampling and then soil samples below, the selected plants were collected at a depth between 0 and 30 $\mathrm{cm}$, with three replicates at each sampling site (Chen et al. 2017). Soil samples were collected, mixed, and preserved in an aseptic bag (about $50 \mathrm{~g}$ ). Samples were stored in prepared ice boxes and transferred to the laboratory. The determination of soil moisture refers to the methods described in Chen et al. (2017). The determination of a soil nutrient content refers to the methods described in Sparks et al. (1996).
Photosynthetic parameters: Field measurement of photosynthetic parameters was carried out from 13 June, 2015 to 12 July, 2015, when the cracks in ground subsidence were forming in the study area. The photosynthetic parameters were measured from 10:30 to $11: 30 \mathrm{~h}$ every two days. Photosynthetic $\mathrm{CO}_{2}$ assimilation rate $\left(P_{\mathrm{N}}\right)$, instantaneous water-use efficiency $\left(\mathrm{WUE}=P_{\mathrm{N}} / E\right)$, stomatal conductance $\left(g_{\mathrm{s}}\right)$, and transpiration rate $(E)$ of selected leaves were measured under natural solar irradiance (PPFD: 1,500-1,600 $\mu \mathrm{mol} \mathrm{m} \mathrm{m}^{-2} \mathrm{~s}^{-1}$ ). Leaf chamber temperature was $20-25^{\circ} \mathrm{C}$. Environmental $\mathrm{CO}_{2}$ concentration was 385-400 $\mu \mathrm{mol} \mathrm{mol}{ }^{-1}$. Licor 6400 portable photosynthesis system (Li-Cor, Lincoln, NE, USA) was used. After removing dust from the leaf surface and induction for $30 \mathrm{~min}$ at saturation light intensity, parametric measurements were collected on mature and fully-expanded leaves (Li et al. 2007).

Chlorophyll (Chl) fluorescence and JIP-parameters: Chl fluorescence was measured on leaves, using Handy PEA (Hansatech Instrument, Ltd., UK) in 9:00-11:00 h The light source was red light with a wavelength of $650 \mathrm{~nm}$, and the intensity of illumination was 3,000 $\mu$ mol(photon) $\mathrm{m}^{-2} \mathrm{~s}^{-1}$. The fluorescence signal was recorded with a maximum frequency of $10^{5}$ points $\mathrm{s}^{-1}$ (each $10 \mathrm{~ms}$ ) within 0-0.3 ms (Brestic et al. 2012), after which the frequency of recording gradually decreased collecting a total of 118 points within $1 \mathrm{~s}$, and each leaf was measured three times. Chl fluorescence-induced curve was measured shortly after keeping the selected leaves in dark for $20 \mathrm{~min}$. The main fluorescence parameters $\left(\mathrm{F}_{\mathrm{v}} / \mathrm{F}_{\mathrm{m}}, \mathrm{F}_{\mathrm{v}} / \mathrm{F}_{0}, \mathrm{PI}, \mathrm{M}_{0}, \mathrm{ABS} / \mathrm{RC}, \mathrm{ET}_{\mathrm{o}} / \mathrm{RC}, \mathrm{DI}_{\mathrm{o}} / \mathrm{CS}, \mathrm{ET}_{\mathrm{o}} /\right.$ $\mathrm{TR}_{\mathrm{o}}, \mathrm{DF}_{(\mathrm{abs})}$, and $\mathrm{TR}_{\mathrm{o}} / \mathrm{RC}$ ) were obtained and the specific meanings are described in detail by Yunus et al. (2000) and Singh et al (2015). A summary of the parameters and formulae of Chl fluorescence transients is summarized in Table 3S (supplement). The relative variable fluorescence was calculated according to $\mathrm{Su}$ et al. (2013): $\mathrm{V}_{\mathrm{t}}=\left(\mathrm{F}_{\mathrm{t}}-\mathrm{F}_{0}\right) /$ $\left(\mathrm{F}_{\mathrm{m}}-\mathrm{F}_{0}\right)$ and $\Delta \mathrm{V}_{\mathrm{t}}=\mathrm{V}_{\mathrm{tSA}}-\mathrm{V}_{\mathrm{tCK}}$. The $\Delta \mathrm{K}$-band, $\Delta \mathrm{J}$-band, and $\Delta \mathrm{I}$-band were measured respectively for $300 \mathrm{~s}, 2 \mathrm{~ms}$, and $30 \mathrm{~ms}$ for determination of $\Delta \mathrm{V}_{\mathrm{t}}$ (Su et al. 2013).

Statistical analysis was performed to test for differences in means for gas-exchange parameters including $P_{\mathrm{N}}, E$,

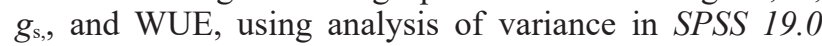
(Statsoft Inc., Tulsa, Oklahoma, USA). The gas-exchange parameters were calculated on the basis of von Caemmerer and Farquhar (1981) model. The Chl fluorescence-induced curve and fluorescence parameters were computed using the data analysis software Origin, version 8.0 (OriginLab Inc., Northampton, Massachusetts, USA). The regression analysis of photosyntheic rate and stomatal conductance was conducted also using the data analysis software Origin, version 8.0 (OriginLab Inc., Northampton, Massachusetts, USA). The SPSS software 19.0 was used to analyze the correlation between the environmental factors and the photosynthetic parameters. 


\section{Results}

Photosynthesis parameters in three plant leaves: The $P_{\mathrm{N}}$ in Populus spp., C. korshinskii, and A. ordosica in SA were 18.26, 23.66, and $13.19 \mu \mathrm{mol}\left(\mathrm{CO}_{2}\right) \mathrm{m}^{-2} \mathrm{~s}^{-1}$, respectively (Table 1). Compared with $\mathrm{CK}$, the $P_{\mathrm{N}}$ decreased by $15.7,15.5$, and $9.9 \%$, respectively. The $g_{\mathrm{s}}$ in Populus spp., C. korshinskii, and A. ordosica in SA were $0.23,0.30$, and $0.19 \mathrm{~mol} \mathrm{~m}^{-2} \mathrm{~s}^{-1}$, respectively (Table 1). The $g_{\mathrm{s}}$ decreased by 23.1 and $42.4 \%$ in $C$. korshinskii and $A$. ordosica, respectively, compared with CK. However, the $g_{\mathrm{s}}$ in Populus spp. decreased only slightly by $4.2 \%$. The $E$ in Populus spp., C. korshinskii, and A. ordosica in SA were $7.04,8.43$, and $8.19 \mathrm{mmol} \mathrm{m}^{-2} \mathrm{~s}^{-1}$, respectively (Table 1). The $E$ of three kinds of plants was reduced by 15.6, 12.9, and 6.1\%, respectively. The WUE in Populus spp., C. korshinskii, and A. ordosica was $2.65,2.76$, and $1.63 \mu \mathrm{mol} \mathrm{mol}{ }^{-1}$, with reductions of $3.6,4.5$, and $3.6 \%$, respectively. No significant difference was found in WUE of the three plants under both conditions. However, significant differences of $P_{\mathrm{N}}$ and $g_{\mathrm{s}}$ were detected between the two conditions (Fig. 2).

Table 1. Gas-exchange parameters for comparison of the effects of coal mining subsidence on three species between SA and CK.

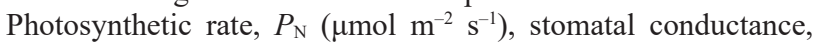
$g_{\mathrm{s}}\left(\mathrm{mol} \mathrm{m} \mathrm{m}^{-2} \mathrm{~s}^{-1}\right)$, transpiration rate, $E\left(\mathrm{mmol} \mathrm{m} \mathrm{m}^{-2} \mathrm{~s}^{-1}\right)$, and wateruse efficiency, WUE $\left(\mu \mathrm{mol} \mathrm{mol}{ }^{-1}\right)$. The $\%$ column represents the relative differences in SA vs. CK. Gas-exchange parameters with significant difference between the two different areas are highlighted with ${ }^{*}-p<0.05$ and ${ }^{* *}-p<0.01$. All tests were conducted at the significance level of 0.05 . Data are mean \pm S.D. $(n=27)$.

\begin{tabular}{lllll}
\hline Plant & Parameter & SA & CK & $\%$ \\
\hline Populus spp. & $P_{\mathrm{N}}{ }^{* *}$ & $18.26 \pm 2.93$ & $21.66 \pm 2.48$ & 84.30 \\
& $g_{\mathrm{s}}$ & $0.23 \pm 0.07$ & $0.24 \pm 0.06$ & 95.83 \\
& $\mathrm{E}^{*}$ & $7.04 \pm 0.97$ & $8.34 \pm 0.44$ & 84.41 \\
& WUE & $2.65 \pm 0.30$ & $2.75 \pm 0.66$ & 96.36 \\
C. korshinskii & $P_{\mathrm{N}}{ }^{* *}$ & $23.66 \pm 1.85$ & $27.99 \pm 3.41$ & 84.53 \\
& $g_{\mathrm{s}}{ }^{*}$ & $0.30 \pm 0.12$ & $0.39 \pm 0.14$ & 76.92 \\
& $\mathrm{E}^{* *}$ & $8.43 \pm 0.42$ & $9.68 \pm 0.68$ & 87.09 \\
& WUE & $2.76 \pm 0.22$ & $2.89 \pm 0.23$ & 95.50 \\
A. ordosica & $P_{\mathrm{N}}{ }^{*}$ & $13.19 \pm 3.79$ & $14.64 \pm 4.17$ & 90.09 \\
& $g_{\mathrm{s}}{ }^{* *}$ & $0.19 \pm 0.09$ & $0.33 \pm 0.17$ & 57.58 \\
& $\mathrm{E}^{*}$ & $8.19 \pm 0.72$ & $8.72 \pm 0.62$ & 93.92 \\
& WUE & $1.63 \pm 0.52$ & $1.69 \pm 0.51$ & 96.45 \\
\hline
\end{tabular}

In Populus spp. and C. korshinskii, $P_{\mathrm{N}}$ tended to increase under the conditions of coal-mining subsidence compared to A. ordosica (Fig. 2). A sustained decrease in $P_{\mathrm{N}}$ was observed in $A$. ordosica after 11:00 a.m. However, the $P_{\mathrm{N}}$ in coal-mining subsidence plants was lesser than that of $\mathrm{CK}$ during the measurement period, although there were some fluctuations (Fig. 2A,E,I). Under the two conditions, the $g_{\mathrm{s}}$ of Populus spp. had similar variation without obvious differences (Fig. 2B). The $g_{\mathrm{s}}$ of $C$. korshinskii and $A$. ordosica in coal-mining subsidence was lesser than that in $\mathrm{CK}$, but the patterns of variations were different. The decrease in $g_{\mathrm{s}}$ in $C$. korshinskii began in 11:15 h, and that of $A$. ordosica began in 10:45 h (Fig. $2 E-F$ ). A sustained increase in $E$ was detected in three species. Throughout the experiment, the $E$ of plants in the subsidence area was lower than that in the control area, and this difference was more obvious in Populus spp. and C. korshinskii (Fig. $2 C-K)$. For WUE, no significant difference was found between Populus spp. and $C$. korshinskii at the end of the measurement. But WUE of A. ordosica in SA was clearly lesser than that in $\mathrm{CK}$. Stomatal limitation was probably the determining factor causing the decrease in $P_{\mathrm{N}}$ (Kozlowski 1984).

Chl fluorescence: In order to further explore the stress of plants caused by cracks in coal mining subsidence, OJIP, (known as an effective probe for the stress state of plants) of leaves was determined. It can provide photochemical information about PSII and accurately and rapidly reflect the electron redox state of the PSII donor side, receptor side, and reaction center in light reactions (Strasser and Strasser 1995, Zhu 1999, Li et al. 2013). Therefore, the response characteristics of the photosynthetic mechanism of plant leaves to mining subsidence cracks were investigated.

The fluorescence curve of three plants in the subsidence area was O-K-J-I-P shaped, while the control area was O-J-I-P (Fig. 3). According to the relative variable fluorescence difference curves of Populus spp. and C. korshinskii, both $\Delta \mathrm{K}$ and $\Delta \mathrm{J}$ were greater than 0 , while $\Delta \mathrm{I}$ was approximately equal to 0 . However, those difference curves of $A$. ordosica, $\Delta \mathrm{K}, \Delta \mathrm{J}$, and $\Delta \mathrm{I}$ were all greater than 0 . In addition, $\Delta \mathrm{K}$ and $\Delta \mathrm{J}$ in Populus spp. was lower than that of $C$. korshinskii and A. ordosica. This indicated that damage and inhibition were more serious in C. korshinskii and A. ordosica than that in Populus spp. The values of $\mathrm{O}$ and $\mathrm{P}$ of the two curves did not vary significantly under both conditions. It shows that the collapse crack had little influence on the $\mathrm{O}$ and $\mathrm{P}$ values (Fig. 3).

Variation characteristics of $\mathrm{Chl}$ fluorescence-induced kinetic parameters under collapse cracks: Fluorescence parameters of leaves of three plant species, obtained by mathematical analysis of the information of fast Chl fluorescence induction kinetic curve, were compared and analyzed under two different conditions (SA and $\mathrm{CK}$ ) (Fig. 4).

Changes in the PSII reaction center: On the basis of active reaction centers (RC), under the stress caused by collapse cracks, the absorbed light energy $(\mathrm{ABS} / \mathrm{RC})$, the captured light energy $\left(\mathrm{TR}_{\mathrm{o}} / \mathrm{RC}\right)$, and the heat dissipated light energy $\left(\mathrm{DI}_{\mathrm{o}} / \mathrm{CS}\right)$ of the unit reaction center increased significantly, compared with CK. But the energy for the electron transport $\left(\mathrm{ET}_{\mathrm{o}} / \mathrm{RC}\right)$ was reduced markedly (Fig. 4). This suggested that plant leaves decreased the energy used for electron transport and increased the heat dissipated energy to reduce the stress damage caused by collapse cracks. The specific activity parameters (ABS/ $\mathrm{RC}, \mathrm{TR}_{\mathrm{o}} / \mathrm{RC}, \mathrm{DI}_{0} / \mathrm{CS}, \mathrm{ET}_{\mathrm{o}} / \mathrm{RC}$ ) of the PSII reaction center illustrated an overall similarity of the three species under the two conditions. 


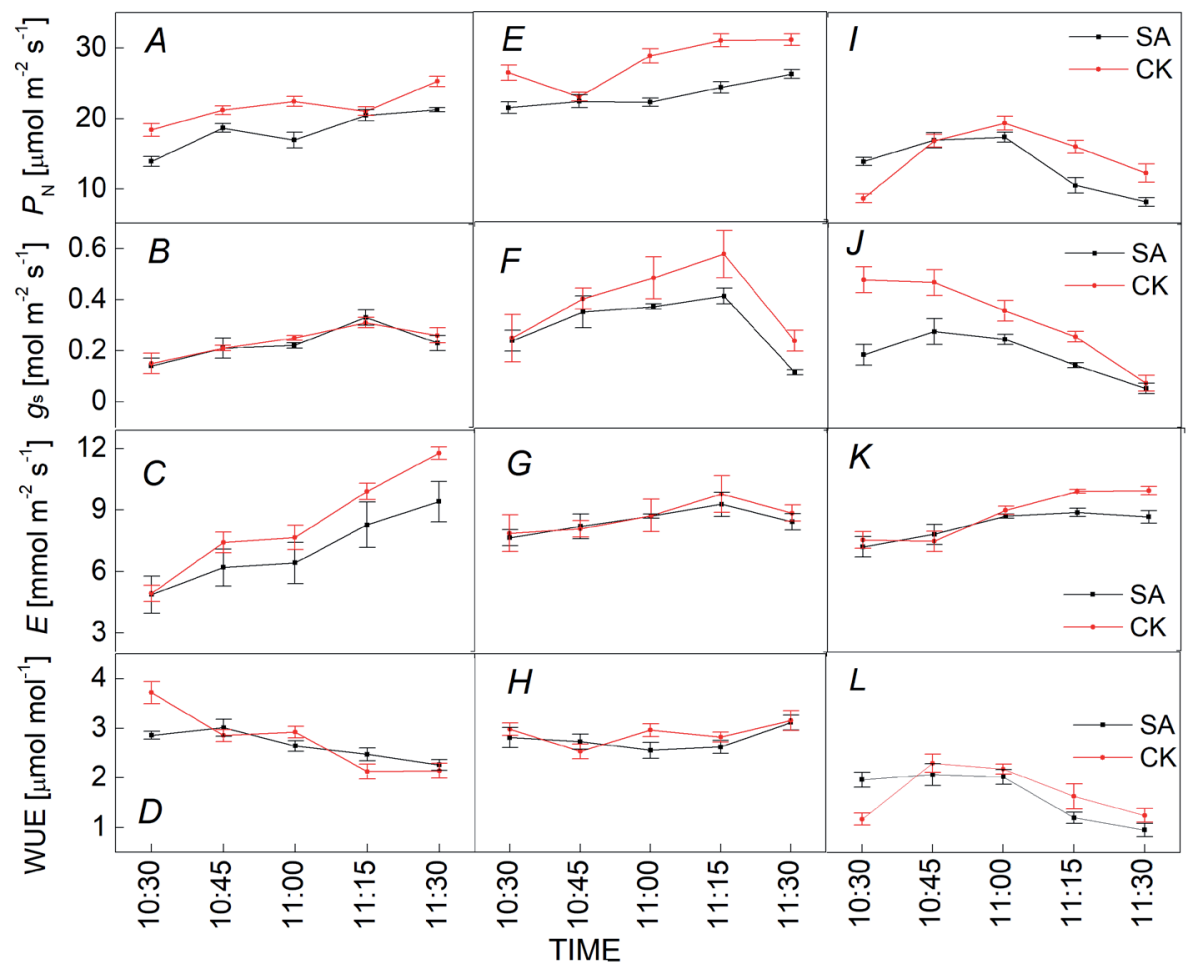

Fig. 2. Temporal variation of photosynthetic parameters to compare the effects of coal mining subsidence on three species between SA (black line) and $\mathrm{CK}$ (red line). Photosynthetic rate $\left(P_{\mathrm{N}}\right)$; stomatal conductance $\left(g_{\mathrm{s}}\right)$; transpiration rate $(E)$; and water-use efficiency (WUE). The four diagrams of the first column, the second column and the third column are the photosynthetic parameters of Populus spp., Caragana korshinskii, and Artemisia ordosica, respectively. Mean $\pm \operatorname{SD}(n=27)$.

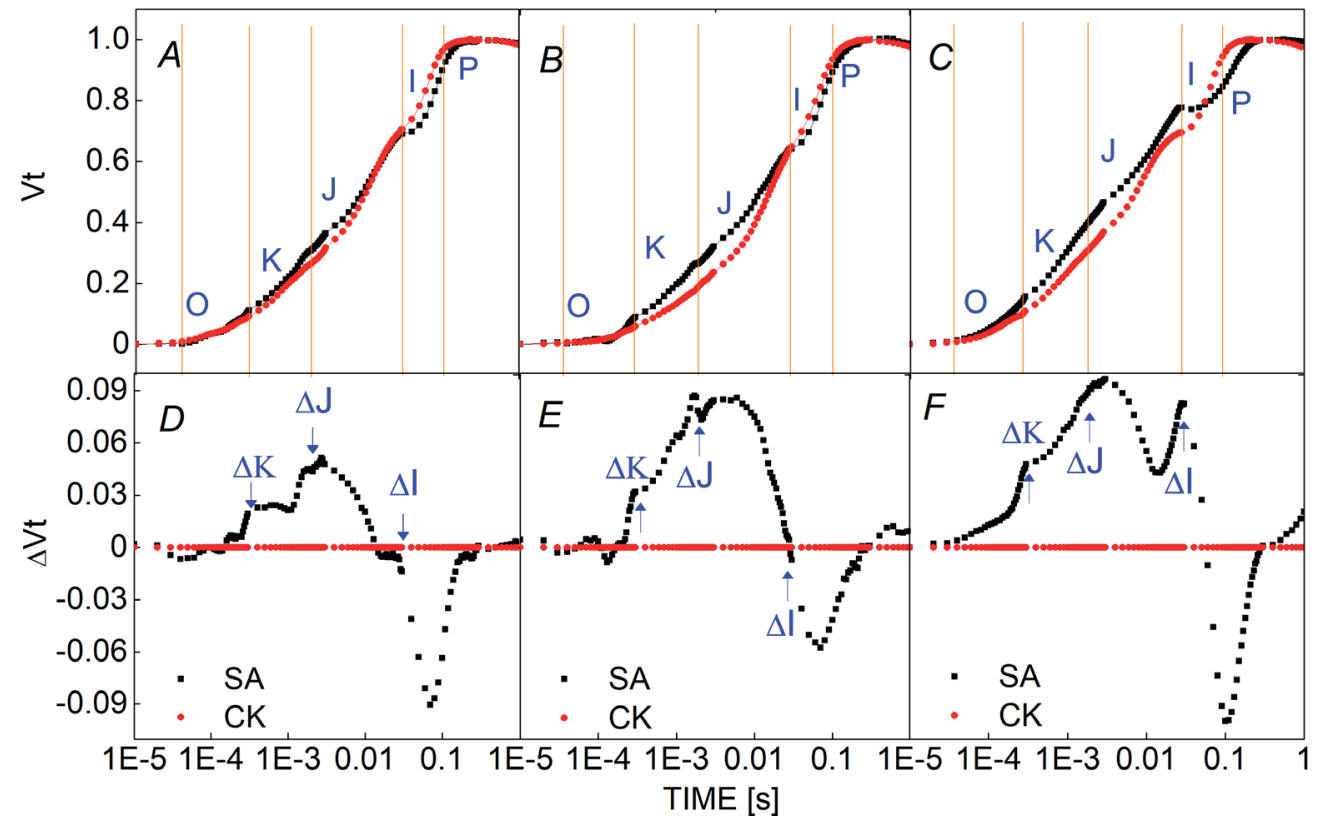

Fig. 3. The relative variable fluorescence induction kinetic curve and relative variable fluorescence difference curve of Populus spp., Caragana korshinskii, and Artemisia ordosica in the collapse crack area (black line) and control area (red line). The means represent nine replications.

Changes in PSII receptor side: The changes of PSII receptor-side parameters were basically the same in the three plants (Fig. 4). The probability of electron transport to an electron acceptor downstream of $\mathrm{Q}_{\mathrm{A}^{-}}\left(\mathrm{ET}_{\mathrm{o}} / \mathrm{TR}_{\mathrm{o}}\right)$, quantum yield for electron transport (ETo/ABS), quantum ratio of heat dissipation $\left(\mathrm{F}_{0} / \mathrm{F}_{\mathrm{m}}\right)$, and PSII maximum quantum efficiency $\left(\mathrm{TR}_{\mathrm{o}} / \mathrm{ABS}\right)$ decreased in different degrees under the collapse-crack conditions compared with $\mathrm{CK}$. These results indicated that the electron transport activity of leaves in three plants in the collapse-crack area was inhibited and the activity decreased. Electron transport was blocked, resulting in a decrease in the probability of electron transport to electron acceptors downstream of $\mathrm{Q}_{\mathrm{A}}{ }^{-}$ $\left(\mathrm{ET}_{\mathrm{o}} / \mathrm{TR}_{\mathrm{o}}\right)$, and more light energy was used to restore $\mathrm{Q}_{\mathrm{A}}$, which eventually accelerated the reduction $\left(\mathrm{M}_{0}\right)$ of $\mathrm{Q}_{\mathrm{A}}$.

Change of leaf performance index: In the collapse crack area, $\mathrm{F}_{\mathrm{v}} / \mathrm{F}_{\mathrm{m}}$ of three plant species was less than 0.8 , and 

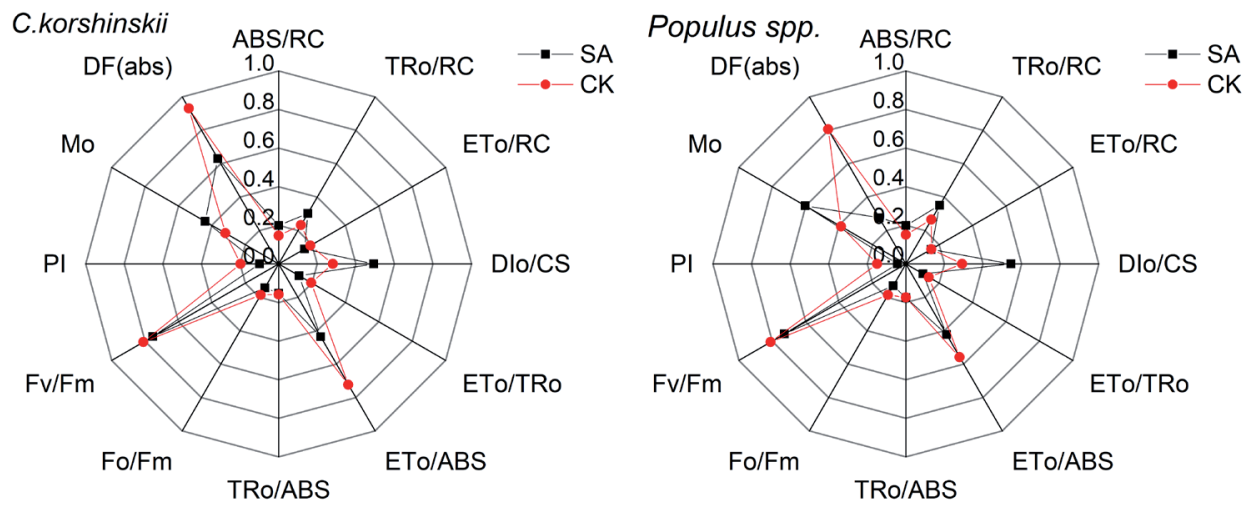

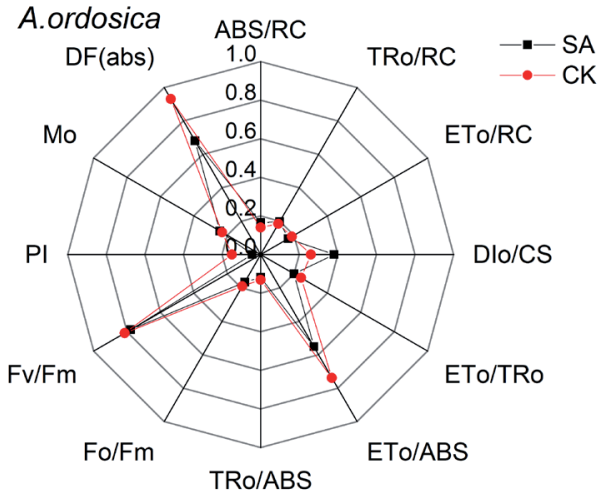

that of plants in CK was higher than 0.8 (Fig. 4). The plant performance index $\mathrm{PI}_{\mathrm{ABS}}$, which can accurately reflect the state of plant light and organization (Strasser et al. 2004), was further analyzed. PI is a performance index based on the absorption of light energy, which can accurately reflect the overall state of the plant photosynthetic apparatus (van Heerden et al. 2004). Compared with the CK, the $\mathrm{PI}_{\mathrm{ABS}}$ of the plant leaves in the collapse crack area decreased significantly. This indicated that the collapse cracks might cause plant stress, damaged the function of photosynthetic organs, reduced the efficiency of light conversion, and limited the normal progress of photosynthesis. This results is consistent with the $\mathrm{F}_{\mathrm{v}} / \mathrm{F}_{\mathrm{m}}$ analysis.

Potential impact factors caused by collapse cracks on photosynthesis and $\mathrm{Chl}$ fluorescence: The topographic elements and illumination conditions were not included in the analysis, mainly because those of all the plants tested were basically consistent with each other.

Soil water content (SWC) was significantly negatively correlated with $\mathrm{ABS} / \mathrm{RC}, \mathrm{TR}_{\mathrm{o}} / \mathrm{RC}$, and $\mathrm{DI}_{\mathrm{o}} / \mathrm{CS}$, with correlation coefficients of $-0.79,-0.90$, and -0.86 , respectively (Table 2). Significant positive correlation was found between SWC and PI, $E, \mathrm{~F}_{0} / \mathrm{F}_{\mathrm{m}}$, and $g_{\mathrm{s}}, P_{\mathrm{N}}, \mathrm{ET}_{0} /$ $\mathrm{ABS}, \mathrm{ET}_{0} / \mathrm{TR}_{0}$, with correlation coefficients of $0.63,0.60$, $0.70,0.78,0.75,0.72$, and 0.80 , respectively. Moreover, SWC was positively correlated with $\mathrm{F}_{\mathrm{v}} / \mathrm{F}_{\mathrm{m}}$, although they were not significant at 0.01 and 0.05 levels. In addition, other environmental factors showed some correlation with photosynthetic parameters of individual plants, but in general, correlation was not significant at 0.01 and 0.05 levels. This showed that SWC was the main factor
Fig. 4. Conventional parameters of leaves of Populus spp., Caragana korshinskii, and Artemisia ordosica were compared and analyzed in the collapse crack area (black column) and control area (red column). The means represent nine replications.

affecting plant photosynthesis and Chl fluorescence in the collapse crack area.

As a whole, 0-60-cm soil water content decreased significantly (Fig. 5A), despite the impact of rainfall. Compared to the state before the mining collapse, the soil infiltration rate clearly increased (Fig. $5 B$ ) and soil compactness decreased by different degrees (Fig. 5C). Under the influence of coal mining subsidence, the water-

Table 2. The correlation between plant photosynthetic physiological parameters and environmental factors. $\mathrm{C}\left(\mathrm{CO}_{2}\right)_{-}$ concentration of $\mathrm{CO}_{2}$ in the environment; $\mathrm{SWC}$ - soil water content; $\mathrm{OM}$ - organic matter; TN - total nitrogen; TP - total phosphorus; AN - ammonia nitrogen. ${ }^{* *}$ - significant at the 0.01 level, ${ }^{*}$ - significant at the 0.05 level.

\begin{tabular}{llllllll}
\hline Parameter & $\mathrm{C}\left(\mathrm{CO}_{2}\right)$ & $\mathrm{SWC}$ & $\mathrm{OM}$ & $\mathrm{TN}$ & $\mathrm{TP}$ & $\mathrm{AN}$ & $\mathrm{BD}$ \\
\hline $\mathrm{F}_{\mathrm{v}} / \mathrm{F}_{\mathrm{m}}$ & 0.47 & 0.55 & 0.48 & $0.62^{*}$ & 0.16 & 0.19 & -0.32 \\
$\mathrm{PI}$ & 0.23 & $0.63^{*}$ & -0.56 & -0.42 & $-0.61^{*}$ & -0.56 & 0.45 \\
$\mathrm{Mo}$ & -0.29 & -0.27 & $0.61^{*}$ & 0.45 & $0.63^{*}$ & 0.46 & 0.21 \\
$\mathrm{ABS} / \mathrm{RC}$ & -0.52 & $-0.79^{* *}$ & $0.70^{*}$ & 0.57 & 0.34 & $0.66^{*}$ & 0.44 \\
$\mathrm{TR}_{0} / \mathrm{RC}$ & -0.54 & $-0.90^{* *}$ & 0.52 & 0.33 & 0.37 & $0.71^{* *}$ & 0.49 \\
$\mathrm{DI}_{0} / \mathrm{CS}$ & $-0.61^{*}$ & $-0.86^{* *}$ & $0.65^{*}$ & 0.45 & 0.43 & $0.75^{* *}$ & 0.25 \\
$\mathrm{ET}_{0} / \mathrm{RC}$ & -0.53 & -0.39 & 0.11 & 0.17 & 0.15 & 0.07 & 0.37 \\
$E$ & 0.19 & $0.60^{*}$ & -0.27 & -0.05 & 0.03 & -0.37 & 0.41 \\
$g_{\mathrm{s}}$ & 0.47 & $0.78^{* *}$ & -0.41 & -0.17 & -0.05 & -0.50 & -0.37 \\
$P_{\mathrm{N}}$ & $0.59^{*}$ & $0.75^{* *}$ & -0.20 & 0.11 & 0.05 & -0.34 & 0.22 \\
$\mathrm{~F}_{0} / \mathrm{F}_{\mathrm{m}}$ & 0.49 & $0.70^{*}$ & -0.08 & 0.15 & 0.08 & -0.31 & 0.37 \\
$\mathrm{ET}_{0} / \mathrm{ABS}$ & 0.72 & $0.72^{* *}$ & 0.11 & 0.23 & -0.05 & -0.11 & -0.40 \\
$\mathrm{TR}_{0} / \mathrm{ABS}$ & -0.14 & 0.08 & $-0.78^{* *}$ & $-0.83^{* *}$ & 0.47 & -0.56 & 0.29 \\
$\mathrm{ET}_{0} / \mathrm{TR}_{0}$ & $0.62^{*}$ & $0.80^{* *}$ & -0.47 & -0.45 & -0.30 & -0.45 & 0.05 \\
\hline
\end{tabular}




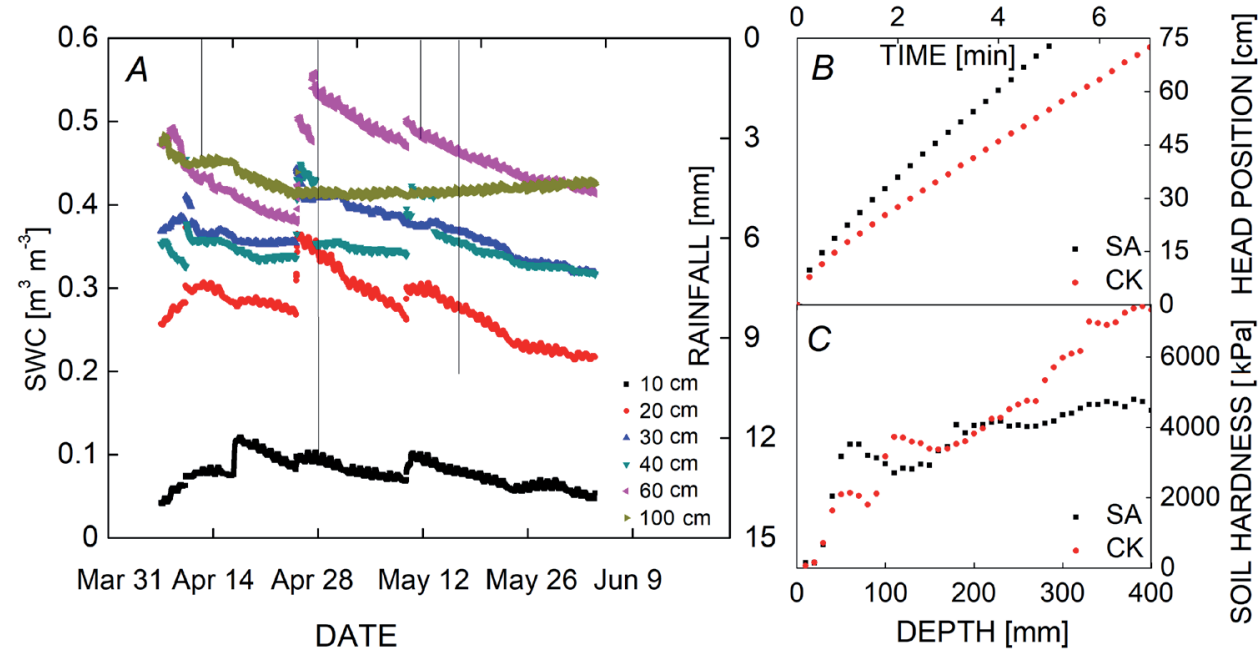

and semiarid mining areas, which leads to the decrease of surface water and wetland area, and finally affects the recharge of ground water by surface water (Ji et al. 2015, Ma et al. 2015). This is another important reason for the decrease of soil water content in the collapse crack area. Under the influence of coal mining collapse cracks, the soil water content was reduced. In arid and semiarid areas, water is an important limiting factor for plant growth (Ehleringer et al. 1998, Haile and Tsegaye 2002, Fensholt et al. 2012). Low soil water content was further reduced, indicating that plant growth was subjected to drought stress in different degrees. Under these conditions, photosynthesis and Chl fluorescence of plant leaves changed accordingly to cope with drought stress (Fig. 1S, supplement).

In the crack area, under drought stress, despite a series of changes in leaf photosynthesis and Chl fluorescence characteristics, three kinds of plants could grow well, and did not die. It indicated that the three species had the capacity of drought resistance. This was also an important reason why the three plant species had been chosen as ecological restoration species in the mining area. According to Wei et al. (2014) research on the influence of coal mining subsidence on soil characteristics in the aeolian sandy area, there was no obvious difference between the surface and shallow soil nutrient elements in the short term in the subsidence area, which has also been confirmed by our experiments. No significant difference was found in OM, TN, TP, or AN after mining subsidence (data not shown). Because of the low rainfall after the collapse, the soil erosion was not serious, but the changes in $\mathrm{OM}, \mathrm{TN}, \mathrm{TP}, \mathrm{AN}$ were mainly related to the soil erosion caused by rainfall.

Photosynthesis response: The decrease in $P_{\mathrm{N}}$ caused by the subsidence crack was mainly attributed to the closing of stomata and nonstomatal factors (Pezeshki 2001, Li et al. 2007, Herrera et al. 2008). We found a close relationship between $P_{\mathrm{N}}$ and $g_{\mathrm{s}}$ in three plant species (Fig. 6). Particularly in A. ordosica and Populus spp., the $P_{\mathrm{N}}$ increased with the increase of $g_{\mathrm{s}}$, although this pattern was not significant in $C$. korshinskii. In addition, the $P_{\mathrm{N}}$ and $g_{\mathrm{s}}$ obtained from SA plants were lower than those from 


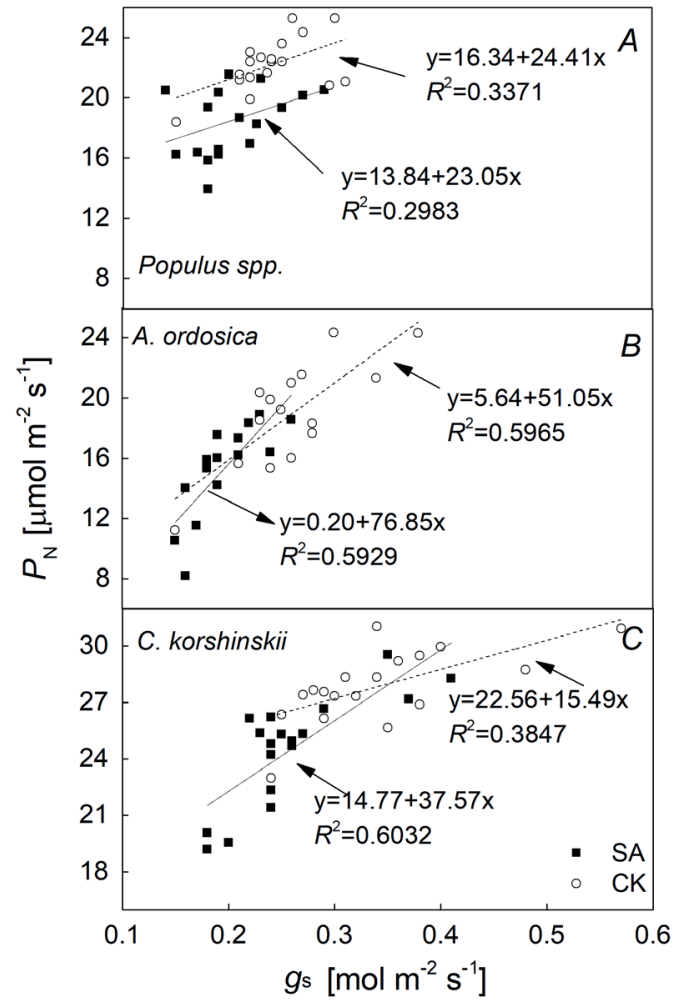

Fig. 6. The relationship between photosynthetic rate $\left(P_{\mathrm{N}}\right)$ and leaf stomatal conductance $\left(g_{\mathrm{s}}\right)$ for three plant species in SA and CK.

CK (Fig. 6). This different response indicated that stomatal limitation, caused by coal mining subsidence, may be the critical factor which affected photosynthetic rate of plants. This result was similar to the response of alfalfa (Wan et al. 2009), although similar data have rarely been reported to interpret the effects of collapsed cracks on plants.

As expected, the photosynthetic characteristics of Populus spp., C. korshinskii, and A. ordosica showed different responses to drought stress, caused by mining collapse cracks. Drought stress can significantly inhibit plant photosynthetic rate (Hu et al. 2010). In this study, the $P_{\mathrm{N}}$ was drastically reduced in all three kinds of plants. Based on their overall response, all three species were sensitive to drought stress, although Populus spp. and C. korshinskii were more sensitive than A. ordosica. This discordance may be partially explained by the wider ecological fitness and stronger drought resistance of A. ordosica. The $g_{\mathrm{s}}$ followed the same pattern of change as $P_{\mathrm{N}}$ (Fig. 6). The decrease of $P_{\mathrm{N}}$ was accompanied by a pronounced reduction of $g_{\mathrm{s}}$. Moreover, the $g_{\mathrm{s}}$ and $P_{\mathrm{N}}$ in SA were lower than those in CK. This indicated that the reduction of $P_{\mathrm{N}}$ after drought stress could be attributed mainly to stomatal limitation, although it may also have been affected by nonstomatal factors. In many studies, the stomatal response was closely related to photosynthetic rate and water shortage (Bennett et al. 1987, Mielke et al. 2003, Gómez del Campo 2007). This suggested that stomatal limitation was the critical factor reducing $P_{\mathrm{N}}$ of plants under the influence of mining collapse cracks, which resulted in decreased soil moisture.

Stomata are important channels for the exchange of gas and water between plant leaves and the external environment, and play a key role in regulating the water status of plants (Leonhardt et al. 1997, Chaerle and Straeten 2007). Transpiration played an important role in maintaining water balance in plants, while soil water content was one of the most important factors affecting plant transpiration rate (Zhu et al. 2015). Part of water was absorbed by plant roots was lost through leaf transpiration, and part of them were involved in plant physiological activities (Waring and Running 1976). Generally, the main factor affecting plant transpiration rate was light intensity when soil moisture was sufficient. In the semiarid area, under the condition of consistent illumination, the soil water content was obviously insufficient, and the subsidence associated with coal mining has aggravated the soil water stress in the subsidence area. Under this condition, the stomata were closed, in order to reduce the water loss and improve the WUE in plants (Bao et al. 2016, Li et al. 2014). This was the main reason for the decrease of $E$ and the increase of WUE in plant leaves.

Chl fluorescence response: The cracks of coal mining subsidence aggravated soil moisture loss, and affected the Chl fluorescence response in plant leaves (Figs. 3, 4). Through OJIP curve, the photochemical information about plant PSII can be provided (Li et al. 2013), accurately and rapidly reflecting the electron redox state at the PSII donor side, acceptor side, and reaction center in the light reaction, so as to ascertain the effect of mining subsidence on the photosynthetic mechanism of the plant leaf (Strasser et al. 2004, Li et al. 2013). The OJIP-test parameters were the indexes to test the degree of plant damage (Ma et al. 2010).

The presence of $\mathrm{K}$ and J points means that the oxygenevolving complex (OEC) of the PSII donor side in collapse crack area was damaged and electron transfer from the primary quinone receptor $\left(\mathrm{Q}_{\mathrm{A}}^{-}\right)$to the secondary quinone receptor $\left(\mathrm{Q}_{\mathrm{B}}\right)$ was inhibited. It led to a large accumulation of $\mathrm{Q}_{A^{-}}$, and the emergence of $\Delta \mathrm{I}$, which were mainly associated with the inactivation of the oxidoreductase of ferredoxin in PSI. This leads to a decrease of $\mathrm{Q}_{\mathrm{B}}{ }^{2-}$ synthesis in A. ordosica (Strasser et al. 2002, 2004, 2008; Bussotti 2004). In this study, both $\Delta \mathrm{K}$ and $\Delta \mathrm{J}$ were higher than 0 , compared to CK (Fig. 3), suggesting that OEC suffered significant damage, and the transfer of electrons at the donor side and the recipient side of PSII was blocked, which resulted in an increase in $\mathrm{Q}_{{ }^{-}}{ }^{-}$accumulation under drought stress. The reduction of $\mathrm{ET}_{0} / \mathrm{TR}_{0}$ and $\mathrm{ET}_{0} / \mathrm{ABS}$ also showed that the electron transport ability of PSII receptor decreased continuously (Fig. 4). Under the stress caused by collapse cracks, $\mathrm{ABS} / \mathrm{RC}, \mathrm{TR}_{\mathrm{o}} / \mathrm{RC}$, and $\mathrm{DI}_{0} / \mathrm{CS}$ of the unit reaction center increased significantly and $\mathrm{ET}_{0} / \mathrm{RC}$ was reduced markedly, compared with CK. This suggested that plant leaves lowered the energy used for electron transport and increased the heat dissipated energy to reduce the stress damage caused by collapse cracks. $\mathrm{F}_{\mathrm{v}} / \mathrm{F}_{\mathrm{m}}$ can indicate the response of plants to stress (Mi 2009) and the decline of $\mathrm{F}_{\mathrm{v}} / \mathrm{F}_{\mathrm{m}}$ is an important indicator of photoinhibition in plants (Meng et al. 1996, Wang et al. 2004). Normally, $\mathrm{F}_{\mathrm{v}} / \mathrm{F}_{\mathrm{m}}$ after dark adaptation was greater than 0.8 , however, when $\mathrm{F}_{\mathrm{v}} / \mathrm{F}_{\mathrm{m}}$ was less than 0.8 , it was an indication that plants 
were stressed, leading to photoinhibition (Demmig and Björkman 1987, Johnson et al. 1993). This indicated that plant leaves in mining subsidence crack area were affected by photoinhibition, and the maximum photochemical efficiency was reduced, which resulted in plant growth under stress. But many studies found that $\mathrm{F}_{\mathrm{v}} / \mathrm{F}_{\mathrm{m}}$ was not very sensitive to stress (Appenroth et al. 2001, Strasser et al. 2002, Mi 2009, Qiu et al. 2012). The PI indicator is a performance index based on the absorption of light energy, which can accurately reflect the overall state of the plant photosynthetic apparatus (van Heerden et al. 2004). In this study, under drought stress, the reduction of PI and $F_{v} / F_{m}$ was lower than 0.8 (Fig. 4), suggesting that the function of plant photosynthetic apparatus was harmed, which reduced the efficiency of light energy transformation and limited the normal progress of photosynthesis.

To sum up, the coal mining subsidence formed cracks in the surface, which led to the decrease of soil moisture content in the semiarid mining area, and thus resulted in drought stress on plants. Under such conditions, the activity of the PSII reaction center in leaves decreased, and the transfer of electrons at the donor side and the acceptor side of PSII was limited. Finally, the photosynthetic ability of plant leaves was reduced. In addition, coal mining subsidence may lead to root strain and microbial community equilibrium disruption (Fig. 1S). In this paper, the effects of coal mining subsidence on plant photosynthesis and Chl fluorescence were analyzed from the point of view of the decrease in soil water content at the surface soil. The effects of plant root strain and root microbial balance damage on photosynthesis and Chl fluorescence in plants should be further studied.

Conclusion: The impact of coal mining on the ecological environment has attracted widespread attention. In this paper, photosynthesis and chlorophyll fluorescence characteristics of typical plants under the influence of coal mining subsidence cracks were studied. The profound effect of ground cracks, caused by coal mining, on plant photosynthetic physiology was revealed. The results showed that compared with the control area, stomatal conductance, photosynthetic rate, and transpiration rate of the three plants were significantly reduced. The rapid chlorophyll fluorescence induction curve was deformed and changed from O-J-I-P to O-K-J-I-P. The reason was that the existence of cracks in the coal mining subsidence area increased the evaporation surface for soil moisture, reduced the soil water-holding capacity, and reduced the ground-water level, which limited the recharge of ground water to the soil water content. Eventually, further reduction in soil water content, which was very low in the arid area, resulted in drought stress. Under drought stress, stomatal conductance and the activity of PSII reaction center decreased, and the electron transport at the donor and acceptor sites was limited. Finally, the photosynthetic capacity of plant leaves was reduced. These finding provide a theoretical basis for ecological protection and ecological restoration of vegetation in arid mining areas.

\section{References}

Appenroth K. J., Stöckel J., Srivastava A. et al.: Multiple effects of chromate on the photosynthetic apparatus of Spirodela polyrhiza as probed by OJIP chlorophyll a fluorescence measurements. - Environ. Pollut. 115: 49-64, 2001.

Bao J., Wang J., Su J.: Photosynthetic properties and water use characteristics in in different ages. - J. Desert Res. 36: 199205, 2016.

Bennett J.M., Sinclair T.R., Muchow R.C. et al.: Dependence of stomatal conductance on leaf water potential, turgor potential, and relative water content in field-grown soybean and maize. - Crop Sci. 27: 984-990, 1987.

Bian Z.F.: Research on the recultivation and ecological reconstruction in coal mining area in China. - Resour. Ind. 7: 18-24, 2005.

Brestic M., Zivcak M., Kalaji H.M. et al.: Photosystem II thermostability in situ: Environmentally induced acclimation and genotype-specific reactions in Triticum aestivum L. Plant Physiol. Bioch. 57: 93-105, 2012.

Bussotti F.: Assessment of stress conditions in L. leaves by O-JI-P chlorophyll fluorescence analysis. - Plant Biosyst. 138: 101-109, 2004.

Chaerle L., Straeten D.V.D.: Regulating Plant Water Status by Stomatal Control. Pp. 73-90. Springer, Dordrecht 2007.

Chen X.W., Wong J.T., Leung A.O. et al.: Comparison of plant and bacterial communities between a subtropical landfill topsoil 15years after restoration and a natural area. - Waste Manage. 63: 49-57, 2017.

Dąbrowski P., Baczewska A.H., Pawluśkiewicz B. et al.: Prompt chlorophyll $a$ fluorescence as a rapid tool for diagnostic changes in PSII structure inhibited by salt stress in Perennial ryegrass. - Photochem. Photobiol. 157: 22-31, 2016.

Dąbrowski P., Kalaji M.H., Baczewska A.H. et al.: Delayed chlorophyll a fluorescence, MR 820, and gas exchange changes in perennial ryegrass under salt stress. - J. Lumin. 183: 322-333, 2017.

Dąbrowski P., Pawluskiewicz B., Baczewska A.H. et al.: Chlorophyll $a$ fluorescence of perennial ryegrass (Lolium perenne $L$.) varieties under long term exposure to shade. Zemdirbyste 102: 305-312, 2015.

Daniels J.L.: Spatio-temporal variation of vegetation in an arid and vulnerable coal mining region. - Mining Sci. Technol. 20: 485-490, 2010.

Demmig B., Björkman O.: Comparison of the effect of excessive light on chlorophyll fluorescence $(77 \mathrm{~K})$ and photon yield of $\mathrm{O}_{2}$ evolution in leaves of higher plants. - Planta 171: 1987.

Ding Y.L., Lei S.G., Bian Z.F. et al.: Distortion-resistant ability of Tetraena mongolica root at the mining subsidence area. - J. China Univ. Min. \& Tech. 42: 970-974, 2013. [In Chinese]

Du T., Bi Y.L., Ju H. et al.: Effects of surface cracks caused by coal mining on microorganisms and enzyme activities in rhizosphere of Salix psammophila. - J. China Coal Soc. 38: 2221-2226, 2013.

Ehleringer J.R., Schwinning S., Gebauer R.: Water use in arid land ecosystems. In: Physiology and Plant Ecology. Pp. 347365. Blackwell Science, Boston 1998.

Fensholt R., Langanke T., Rasmussen K. et al.: Greenness in semi-arid areas across the globe 1981-2007 - an Earth Observing Satellite based analysis of trends and drivers. Remote Sens. Environ. 121: 144-158, 2012.

Gómez del Campo M.: Effect of water supply on leaf area development, stomatal activity, transpiration, and dry matter production and distribution in young olive trees. - Aust. J. Agr. Res. 58: 385-391, 2007.

Haile M., Tsegaye D.: Water harvesting for crop production in 
semi-arid areas of North Eastern Ethiopia, a case study of floodwater diversion in Aba'ala Agro-Pastoral Area. Mekele University, Mekele 2002.

Herrera A., Tezara W., Marín O. et al.: Stomatal and non-stomatal limitations of photosynthesis in trees of a tropical seasonally flooded forest. - Physiol. Plantarum 134: 41-48, 2008.

$\mathrm{Hu}$ L., Wang Z., Huang B.: Diffusion limitations and metabolic factors associated with inhibition and recovery of photosynthesis from drought stress in a $\mathrm{C}$ perennial grass species. - Physiol. Plantarum 139: 93-106, 2010.

Ji R.J., Peng S.P., Fan L.M. et al.: Effect of coal exploitation on groundwater circulation in the Shenfu mine area: An example from middle and lower reaches of the Kuye River basin. - J. China Coal Soc. 40: 938-943, 2015. [In Chinese]

Johnson G.N., Young A.J., Scholes J.D. et al.: The dissipation of excess excitation energy in British plant species. - Plant Cell Environ. 16: 673-679, 1993.

Kozlowski T.T.: Responses of woody plants to flooding and salinity. - In: Flooding \& Plant Growth I. Pp. 129-163. Heron Publishing, Victoria, Canada 1984.

Lei S.G., L., Bian Z.F.: Research progress on the environment impacts from underground coal mining in arid western areaof China. - Acta Ecol. Sin. 34: 2837-2843, 2014. [In Chinese]

Leonhardt N., Marin E., Vavasseur A. et al.: Evidence for the existence of a sulfonylurea- eceptor-like protein in plants: modulation of stomatal movements and guard cell potassium channels by sulfonylureas and potassium channel openers. P. Natl. Acad. Sci. USA 94: 14156-14161, 1997.

Li M., Yang D., Li W.: Leaf gas exchange characteristics and chlorophyll fluorescence of three wetland plants in response to long-term soil flooding. - Photosynthetica 45: 222-228, 2007.

Li X.X., Liu B.X., Guo Z.T. et al.: [Effects of $\mathrm{NaCl}$ stress on photosynthesis characteristics and fast chlorophyll fluorescence induction dynamics of Pistacia chinensis leaves.] - J. Appl. Ecol. 24: 2479, 2013. [In Chinese]

Li Z.Z., Zhang L., Li S. et al.: Responses of stomata and Kranz anatomy of maize leaves to soil water shortages. - J. Appl. Ecol. 25: 2944-2950, 2014. [In Chinese]

Ma Q., Lou J.Q., Wang S.M.: Effect of $\mathrm{Na}^{+}$on photosynthetic characteristics of Zygophyllum xanthonylom seedlings under osmotic stress. - Acta Pratacult. Sin. 19: 198-203, 2010. [In Chinese]

Ma X.D., Fan L.M., Zhang X.T. et al.: Driving force analysis for water and wetlands evolution at Yushenfu mining area. - J. China Coal Soc. 40: 1126-1133, 2015.

Ma Y., Huang Y., Wang H. et al.: Effects of collapse fissures caused by coal mining on soil moisture in slope lands after rain. - Acta Pedol. Sin. 51: 497-504, 2014. [In Chinese]

Mastalerczuk G., Borawska-Jarmulowicz B., Kalaji H.M. et al.: Gas-exchange parameters and morphological features of festulolium (Festulolium braunii K. Richert A. Camus) in response to nitrogen dosage. - Photosynthetica 55: 20-30, 2017.

Meng Q., Zhao S., Xu C., Zou Q.: Photoinhibition of photosynthesis and protective effect of photorespiration in winter wheat leaves under field conditions. - Acta Agron. Sin. 22: 470-475, 1996. [In Chinese]

Mielke M.S., de Almeida A.A.F.D., Gomes F.P. et al.: Leaf gas exchange, chlorophyll fluorescence and growth responses of Genipa americana seedlings to soil flooding. - Environ. Exp. Bot. 50: 221-231, 2003.

Pezeshki S.R.: Wetland plant responses to soil flooding. Environ. Exp. Bot. 46: 299-312, 2001.

Qian Z.D., Qin W.H., Shen M.X. et al.: Impacts of coal mining on vegetation landscape in $\mathrm{Mu}$ Us sandland. - Bull. Soil
Water Conserv. 34: 299-303, 2014. [In Chinese]

Qiang L.I., Zhan-Bin L.I., Ke-Xin L.U. et al.: Effect of different underlying surfaces on runoff generation and sediment yield in Shenfu-Dongsheng coal mining area. - Res. Soil Water Conserv. 15: 1-3, 2008.

Qiu H., Jin X., Hu X.: The landscape situation and ecological improvement of coal-mined collapse area in Panji. - In: Int. Conf. Elec. Control Eng. Pp. 4150-4152, 2011.

Qiu N.W., Zhou F., Gu Z.J. et al.: Photosynthetic functions and chlorophyll fast fluorescence characteristics of five Pinus species. - China J. Appl. Ecol. 23: 1181-1187, 2012. [In Chinese]

Roháček K., Soukupová J., Barták M. et al.: Chlorophyll fluorescence: a wonderful tool to study plant physiology and plant stress. - In: Plant Cell Compartments Selected Topics . Pp. 41-104, Research Signpost, Kerala 2008.

Singh S., Prasad S.M.: IAA alleviates Cd toxicity on growth, photosynthesis and oxidative damages in eggplant seedlings. - Plant Growth Regul. 77: 87-98, 2015.

Strasser R.J.: Measuring fast fluorescence transients to address environmental questions. - In: The JIP-Test. Pp. 977-980. Kluwer Academic Publ., Dordrecht-Boston-London 1995.

Strasser R.J., Srivastava A., Govindjee.: Polyphasic chlorophyll $a$ fluorescence transient in plants and cyanobacteria. Photochem. Photobiol. 61: 32-42, 2008.

Strasser R.J., Srivastava A., Tsimilli-Michael M.: The fluorescence transient as a tool to characterize and screen photosynthetic samples. - In: In: Yunus M., Pathre U., Mohanty P. (ed.): Probing Photosynthesis: Mechanisms, Regulation and Adaptation. Pp. 445-483. Taylor \& Francis, London 2000.

Strasser R.J., Tsimilli-Michael M., Srivastava A.: Analysis of the Chlorophyll $a$ Fluorescence Transient. Pp. 321-362. Springer, Dordrecht 2004.

Sparks D.L., Page A.L., Helmke P.A. et al.: Methods of soil analysis. Part III. - In: Chem. Methods. Pp. 141-475. Soil Science Society of America, Madison, Wisconsin, USA 1996

van Heerden P.D., Strasser R.J., Krüger G.H.: Reduction of dark chilling stress in N-2-fixing soybean by nitrate as indicated by chlorophyll a fluorescence kinetics. - Physiol. Plantarum 121: 239, 2004.

von Caemmerer S., Farquhar G.D.: Some relationships between the biochemistry of photosynthesis and the gas exchange of leaves. - Planta 153: 376-387, 1981.

Wan S.M., Jia Z.K., Yang B.P.: Relationship between diurnal changes of alfalfa net photosynthetic rate and environmental factors. - Acta Agrestia Sin. 17: 27-31, 2009. [In Chinese]

Wang B., Xu M., Shi Q. et al.: Effects of high temperature stress on antioxidant systems, chlorophyll and chlorophyll fluorescence parameters in early cauliflower leaves. - Sci. Agr. Sin. 37: 1245-1250, 2004.

Wang C.Y.: A Research of Ecological Environmental Impacts and Ecological Restoration Measures on Gas Field Development. Inner Mongolia University, Hohehot Municipality China 2011.

Wang J., Gao Y., Wei J.S. et al.: Influence of mining subsidence on physical and chemical properties of soil in windy desert area. - J. Soil Water Conserv. 20: 52-55, 2006.

Wang Q., Quan Z., Han Y. et al.: Variation of vegetation diversity and its soil relationship with soil physical and chemical property in lands of different geomorphic types in coal mining subsidence area. - Acta Bot. Boreal. Occident. Sin. 34: 16421651, 2014. [In Chinese]

Waring R.H., Running S.W.: Water uptake, storage and transpiration by conifers: a physiological model. - In: Lange O.L., Kappen L., Schulze E.D. (ed.): Water and Plant Life - Problems and Modern Approaches. Pp. 189-202. Springer 
Berlin Heidelberg 1976.

Wei J.S., He X., Hu C.Y. et al.: Influence of ground collapse caused by coal mining activities on the water characteristics of sandy soil in arid and semi-arid area. - J. Arid Land Res. Environ. 20: 84-88, 2006.

Wei T.T., Hu Z.Q., Cao Y.B. et al.: Impacts of large coal mining on soil and plant characteristics in sandy area. - J. Sichuan Agr. Univ. 4: 376-381, 2014.

Su X.Q., Wang M.Y., Shu S. et al.: Effects of exogenous SPD on the fast chlorophyll fluorescence induction dynamics in tomato seedlings under high temperature stress. - Acta Horticult. Sin. 40: 2409-2418, 2013.

Yunus M., Pathre U., Mohanty P. et al.: Probing Photosynthesis: Mechanisms, Regulation and Adaptation. Pp. 212-278. Taylor and Francis, New York 2000.

Zang Y.T., Wang J., Ding G.D. et al.: Variation of physicochemical properties of aeolian sandy soil at coal mining subsidence and its evaluation. - Acta Pedol. Sin. 47: 262-269, 2010.

Zhang F.W., Hou X.W., Han Z.T. et al.: Impact of coal mining subsidence on soil quality and some protecting technique for the soil quality. - Geogr. Geo.-Inform. Sci. 19: 67-70, 2003.

Zhang H.B., Ma S.C., Ding C. et al.: Effects of the surface cracks caused by coal mining on soil characteristics and wheat growth in Huang-Huai-Hai plain, China. - Appl. Ecol. Environ. Res. 15: 1777-1790, 2017.

Zhang M.: The examination of high temperature stress of Ammopiptanthus mongolicus by chlorophyll fluorescence induction parameters. - Ecol. Environ. Sci. 18: 270-275, 2009. [In Chinese]

Zheng X.: Influence of moisture content on infiltration characteristics in seasonal frozen and thawed soils. - T. Chin. Soc. Agr. Eng. 16: 52-55, 2000. [In Chinese]

Zhu X.G.: Advances in the research on the effects of $\mathrm{NaCl}$ on photosynthesis. - Chin. Bull. Bot. 16: 332-338, 1999. [In Chinese]

Zhu X.J., Yu G.R., Hu Z.M. et al.: Spatiotemporal variations of T/ET (the ratio of transpiration to evapotranspiration) in three forests of Eastern China. - Ecol Indic. 52: 411-421, 2015.

(C) The authors. This is an open access article distributed under the terms of the Creative Commons BY-NC-ND Licence. 